\title{
Distance Relay Algorithm for Tapped Transmission Line
}

\author{
Indumathi $\mathrm{M}^{1}$, Dr. N. Narmadhai ${ }^{2}$ \\ ${ }^{1}$ Department of Electrical and Electronice Engineering, Government College of Technology, Coimbatore \\ ${ }^{2}$ Associate Professor, Department of Electrical and Electronice Engineering, Government College of Technology, Coimbatore
}

\begin{abstract}
The fault location identification is difficult as one has to travel hundreds of kilometer to inspect visually in transmission line. Distance relaying methods are used for protection of transmission lines. In general, pilot relaying is used for protection of transmission line with the help of sending end and receiving end communication system. A distance relay measures the impedance between the fault location and relay point to determine whether a fault is internal or external to a protection zone. This project proposes the distance relay to identify the fault zone. The Western System Coordinating Council (WSCC) 3machine, 9-bus system is taken as test case. The proposed relay method is simulated in MATLAB/Simulink environment. The different faults are created in various buses of test system. The performances of the relay model are plotted. The fault in the test systems are observed from the plot and the command signal is given to trip the circuit breaker.
\end{abstract}

\section{INTRODUCTION}

Power system protection deals with the protection of electrical power systems from faults through the disconnection of faulted parts from the rest of the electrical network. The objective of a protection scheme is to keep the power system stable by isolating the components that are under fault by leaving the network as possible still in operation. Thus, protection schemes must apply a very pragmatic and pessimistic approach to clearing system faults occurring in the power system. The devices that are used to protect the power systems from faults are called protection devices.

A protective relay is device which detects the abnormal conditions on the power system by constantly monitoring the electrical quantities which are different under normal and fault conditions. The basic electrical quantities that change during the fault or abnormal conditions are voltage, current, frequency and phase angle. Protective relays utilize one or two of these quantities to detect the abnormal or fault conditions in the power system.

A distance relay has the ability to detect a fault within a pre-set distance along a transmission line or power cable from its location. In transmission line, the impedance is proportional to its length, for distance measurement it is appropriate to use a relay capable of measuring the impedance of a line up to a predetermined point. Distance relay is designed to operate only for faults occurring between the relay location and the predetermined (reach) point, thus giving discrimination for faults that may occur in different line sections.

Electromechanical relays operate by mechanical forces generated by moving parts due to electromagnetic forces created by the input quantities. Most of the electromechanical relays use either magnetic induction or magnetic attraction principle of operation. Depending on the principle of operation, the electromagnetic relays are of two types namely attracted armature relay and induction relays.

Induction relays have two type of construction. They are one with an induction disc and other with an induction cup. Some electromechanical relays also use electrothermic principle of operation and based on the forces created by expansion of metals caused by temperature rise due to flow of current. Such relays are called thermal relays.

It is not practical to make a relay that develops a torque equal to the quotient of two A.C. quantities. The only significant condition for a relay is its setting and the setting can be made to correspond to a ratio regardless of the component values over a wide range. Several operating coils can be used to provide bias to the relay, allowing the sensitivity of response in one circuit to be controlled by another. Various combinations of operate torque and restraint torque can be produced in the relay. A relay can be responded to current in one direction differently from other by using permanent magnet. Direct-current relays were detected by polarized relays. Reverse current into a generator is an example of these polarized relay. The principle is extended with a polarizing winding connected to a reference voltage source for A.C circuits. The WSCC 9-bus test system IEEE benchmark model which is used in the project contains three synchronous machines with built-in voltage and speed regulators, three two-winding transformers, six constant parameters lines and three loads.

\section{ALGORITHM FOR DISTANCE RELAY IN TAPPED TRANSMISSION LINE}

\section{A. FAULT ON THE TAPPED TRANSMISSION LINE}

Digital distance protection is a universal shortcircuit protection. It's mode of operation is based on the measurement and evaluation of the short-circuit impedance, which is named by the algorithm of digital distance relay.

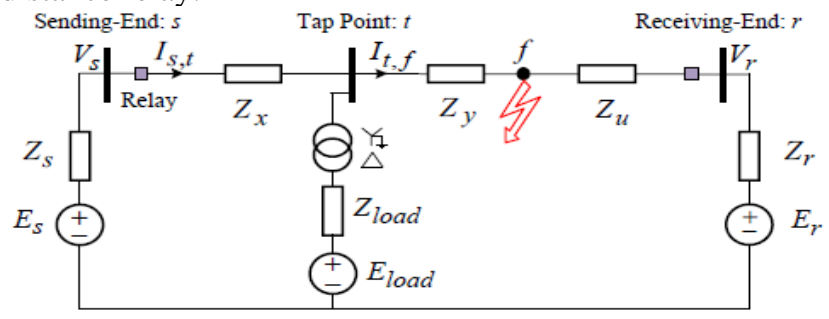

Fig. 1 short-circuit fault on tapped line s-r 
Fig 1 shows a short-circuit fault on the tapped line $s-r$ with length $L$. The tapping transformer is placed at the distance $m L$ from terminal $s$. Fault is assumed to occur at the distance $\alpha L$ from terminal $s$ so that $m<\alpha$. To analyze a 1-ph-g fault at this location by using the method of symmetrical components, the three sequence circuits should be interconnected as shown in Fig. 2. Neglecting the fault resistance, the impedance-to-the-fault is calculated to be

$$
\begin{aligned}
\alpha Z L=[[V s A /(I s, t A & +K I s, t Z)] \\
+ & {\left[\frac{(I s, t A-I t, f A)+(I s, t Z-I t, f Z)}{((I s, t A+K I s, t Z)]}(\alpha\right.} \\
& -m) Z L
\end{aligned}
$$

where the superscripts $A$ and $z$ denote phase- $A$ and zero-sequence quantities, respectively. Conventional distance relays use the simplified formula below to obtain the impedance-to-the-fault:

$$
\text { Zseen }=\frac{\mathrm{VsA}}{\mathrm{Is}, \mathrm{tA}+\mathrm{KOIs,tZ}}
$$

Thus the simplified formula to obtain the impedance-tothe-fault is for phase A and B

$$
\text { Zseen }=\frac{\mathrm{VsA}-\mathrm{VsB}}{I s, t A-I s, t B}
$$

The residual compensation $K 0=(Z 0-Z 1) / K 0 Z 1$. The values of K0 will be 1 or 3 depending on the relay design. Similarly the impedance obtained for other phases are given in the table 1

TABLE 6.1 FORMULA APPLIED FOR THE DIFFERENT TYPES OF FAULT

\begin{tabular}{|c|c|}
\hline Types of Fault & Formula used \\
\hline $\begin{array}{c}\text { Single line to ground } \\
\text { fault(A-G) }\end{array}$ & Zseen $=\frac{V s A}{I s, t A+K 0 I s, t Z}$ \\
\hline $\begin{array}{c}\text { Single line to ground } \\
\text { fault(B-G) }\end{array}$ & $Z$ seen $=\frac{V s B}{I s, t B+K 0 I s, t Z}$ \\
\hline $\begin{array}{c}\text { Single line to ground } \\
\text { fault(C-G) }\end{array}$ & Zseen $=\frac{V s C}{I s, t C+K 0 I s, t Z}$ \\
\hline $\begin{array}{c}\text { Double line Fault or double } \\
\text { line to ground fault (A- } \\
\text { B)(A-B-G) }\end{array}$ & Zseen $=\frac{\mathrm{VsA}-\mathrm{VsB}}{I s, t A-I s, t B}$ \\
\hline $\begin{array}{c}\text { Double line Fault or double } \\
\text { line to ground fault (A-B) } \\
\text { or (A-B-G) }\end{array}$ & Zseen $=\frac{\mathrm{VsB}-\mathrm{VsC}}{I s, t B-I s, t C}$ \\
\hline $\begin{array}{c}\text { Double line Fault or double }-\mathrm{VsA} \\
\text { line to ground fault (A-B) } \\
\text { or (A-B-G) }\end{array}$ & Zs, $t A$ \\
\hline
\end{tabular}

Thus the distance relay algorithm modified formula is implemented for the transmission line using matlab environment

\section{B. CALCULATION TRANSMISSION LINE PARAMETERS}

The WSCC 9-bus system is taken as the test system in order to test the relay operation. The length, per unit resistance, per unit reactance is obtained from the data sheet. The figure 6.2 shows the single line diagram for the WSCC test system.

$$
\mathrm{R}_{\mathrm{act}}=\frac{\mathrm{R}_{\mathrm{pu}}}{\mathrm{R}_{\text {base }}}
$$

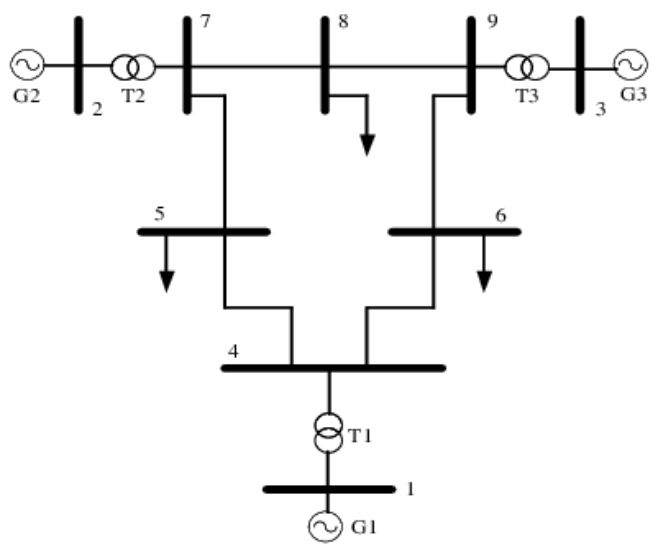

Fig. 2. Single line diagram of WSCC test system

$\mathrm{R}_{1}$ (Positive sequence) $=\frac{\mathrm{R}_{\mathrm{act}}}{\text { Length }}$

$R_{0}($ Zero sequence $)=R_{1} * 3$

$X_{a c t}=X_{p u} * X_{\text {base }}$

$L_{\text {act }}=\frac{X_{\text {act }}}{2 * 3.14 * f}$

$\mathrm{L}_{1}($ Positive sequence $)=\frac{\mathrm{L}_{\text {act }}}{\text { Length }}$

$\mathrm{L}_{0}($ Zero sequence $)=\mathrm{L}_{1} * 3$

$\mathrm{B}_{\mathrm{act}}=\mathrm{B}_{\mathrm{pu}} * \mathrm{~B}_{\text {base }}$

$\mathrm{C}_{\mathrm{act}}=\frac{\mathrm{B}_{\mathrm{act}}}{2 * 3.14 * \mathrm{f}}$

$\mathrm{C}_{1}$ (Positive sequence) $=\frac{\mathrm{C}_{\mathrm{act}}}{\text { Length }}$

\begin{tabular}{|c|c|c|c|}
\hline Line & 4 to 5 & 4 to 6 & 7 to 5 \\
\hline Length(Km) & 97.332 & 95.942 & 176.6297 \\
\hline R_pu(pu) & 0.0100 & 0.0170 & 0.0320 \\
\hline R_base( $(\Omega)$ & 529.00 & 529.000 & 529.0000 \\
\hline R_act $(\Omega)$ & 5.2900 & 8.9930 & 16.9280 \\
\hline R_1 $(\Omega / \mathbf{k m})$ & 0.0544 & 0.0937 & 0.0958 \\
\hline R_o( $\mathbf{Q} / \mathbf{k m})$ & 0.1631 & 0.2812 & 0.2875 \\
\hline X_pu(pu) & 0.0850 & 0.0920 & 0.1610 \\
\hline X_act($(\Omega)$ & 44.965 & 48.6680 & 85.1690 \\
\hline L_act $(\mathbf{H})$ & 0.1193 & 0.1291 & 0.2259 \\
\hline $\mathbf{L} \_\mathbf{1}(\mathbf{H} / \mathbf{k m})$ & 0.00123 & 0.00135 & 0.00128 \\
\hline L_O(H/km) & 0.00368 & 0.00404 & 0.00384 \\
\hline B_pu(pu) & 0.1760 & 0.1580 & 0.3060 \\
\hline B_base(Mho) & $1.89 \mathrm{E}-03$ & $1.89 \mathrm{E}-03$ & $1.89 \mathrm{E}-03$ \\
\hline B_act(Mho) & 3.32E-04 & $2.98 \mathrm{E}-04$ & $5.78 \mathrm{E}-04$ \\
\hline C_act(F) & 8.82E-07 & $7.92 \mathrm{E}-07$ & $1.53 \mathrm{E}-06$ \\
\hline C_1 $1(\mathbf{F} / \mathbf{k m})$ & $9.06 \mathrm{E}-09$ & $8.25 \mathrm{E}-09$ & 8.68E-09 \\
\hline C_0(F/km) & $2.72 \mathrm{E}-08$ & $2.47 \mathrm{E}-08$ & $2.60 \mathrm{E}-08$ \\
\hline
\end{tabular}

$\mathrm{C}_{0}$ (Zero sequence $)=\mathrm{C}_{1} * 3$

The equations from 4-14 are used to obtain the transmission parameters in WSCC test system.

TABLE 2. TRANSMISSION LINE PARAMETERS 
TABLE 3. TRANSMISSION LINE PARAMETERS

\begin{tabular}{|c|c|c|c|}
\hline Line & 7 to 8 & 9 to 8 & 9 to 6 \\
\hline Length(Km) & 82.4232 & 115.5031 & 196.3162 \\
\hline R_pu(pu) & 0.0085 & 0.0119 & 0.0390 \\
\hline R_base( $(\Omega)$ & 529.0000 & 529.0000 & 529.0000 \\
\hline R_act( $(\Omega)$ & 4.4965 & 6.2951 & 20.6310 \\
\hline R_1 $(\Omega / \mathbf{k m})$ & 0.0546 & 0.0545 & 0.1051 \\
\hline R_o( $\mathbf{Q} / \mathbf{k m})$ & 0.1637 & 0.1635 & 0.3153 \\
\hline X_pu(pu) & 0.0720 & 0.1008 & 0.1700 \\
\hline X_act( $(\Omega)$ & 38.0880 & 53.3232 & 89.9300 \\
\hline L_act(H) & 0.1010 & 0.1414 & 0.2385 \\
\hline L_1(H/km) & 0.00123 & 0.00122 & 0.00122 \\
\hline L_O(H/km) & 0.00368 & 0.00367 & 0.00365 \\
\hline B_pu(pu) & 0.1490 & 0.2090 & 0.3580 \\
\hline B_base(Mho) & $1.89 \mathrm{E}-03$ & $1.89 \mathrm{E}-03$ & $1.89 \mathrm{E}-03$ \\
\hline B_act(Mho) & $2.81 \mathrm{E}-04$ & $3.95 \mathrm{E}-04$ & $6.76 \mathrm{E}-04$ \\
\hline C_act(F) & 7.47E-07 & $1.04 \mathrm{E}-06$ & $1.79 \mathrm{E}-06$ \\
\hline C_1(F/km) & $9.06 \mathrm{E}-09$ & 9.07E-09 & $9.14 \mathrm{E}-09$ \\
\hline C_0(F/km) & $2.71 \mathrm{E}-08$ & $2.72 \mathrm{E}-08$ & $2.74 \mathrm{E}-08$ \\
\hline
\end{tabular}

The table 2 and 3 shows the transmission line parameters of the WSCC test system which is designed using the formulae 4-14.

SIMULATION DIAGRAM FOR A TAPPED TRANSMISSION LINE:

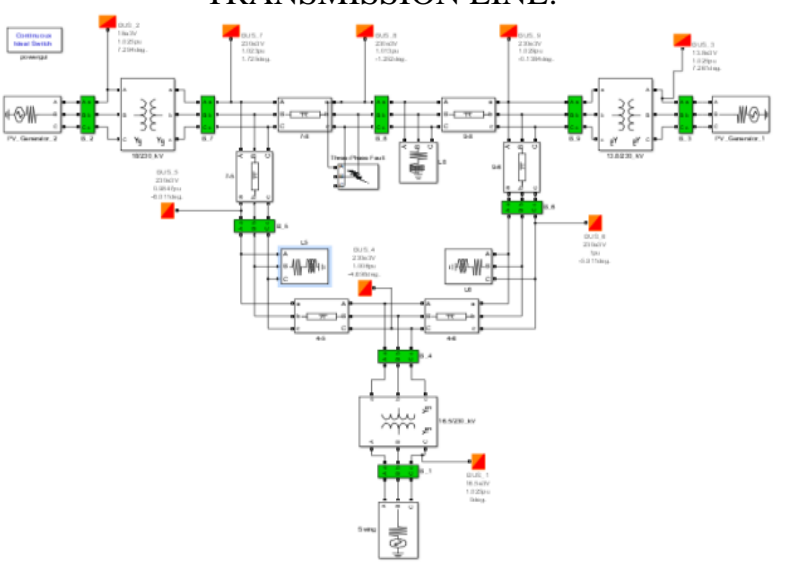

Fig. 3 Simulation diagram for a WSCC test system

This diagram indicates the tapped transmission where the relay is to be implemented. The WSCC 9-bus test system IEEE benchmark is used as the test system to implement the relay algorithm which is mentioned in the project.

WSCC 9-bus test system consists of three generators (at buses 1,2 and 3), three transformers (between the bus pairs 1 and 4,2 and 7,3 and 9), three pi modeled transmission lines (Positive and Zero sequence values of $\mathrm{R}, \mathrm{L}$ and $\mathrm{C}$ were derived and presented in table 6.2.) three loads

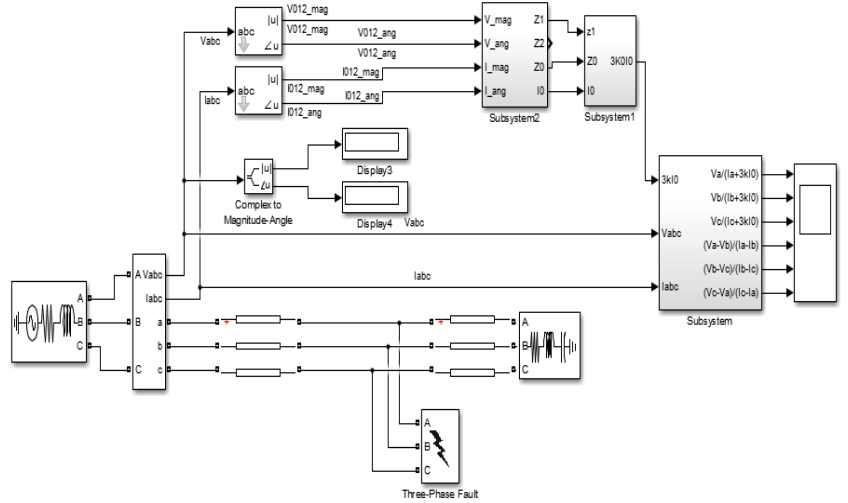

Fig. 4. Simulation diagram of the distance relay algorithm

The test system is WSCC (Western System Coordinating Council) is used in the simulation model. Load flow analysis can provide a balanced steady operation state of the power system, without considering system transient processes. The load flow analysis for the test system is given in the table 7.1. The parameters is obtained from load flow analysis is used for further calculations.

\section{CONCLUSION}

The distance relay algorithm for tapped transmission line was proposed using the modified formula for the single line fault, double line fault and double line to ground fault. The WSCC 9-bus system is used as the test case for testing the relay algorithm. The obtained impedance by using the algorithm is taken as the impedance seen (Zseen) and it is compared with the reference impedance (Zset). The circuit gets tripped when the obtained impedance is less than the impedance which is mentioned in the reference impedance. Thus the transmission line gets protected when the fault is present by using distance relay

\section{REFERENCE}

[1] M. T. N. Dinh, M. Bahadornejad, A. S. A. Shahri, and N. K. C. Nair, "Protection schemes and fault location methods for multiterminal lines: A comprehensive review," in 2013 IEEE Innovative Smart Grid Technologies-Asia (ISGT Asia), pp. 1-6, Nov. 2013.

[2] A. S. Dobakhshari and A. M. Ranjbar, "A wide-area scheme for power system fault location incorporating bad data detection," IEEE Trans. Power Del., vol. 30, no. 2, pp. 800-808, Apr. 2015

[3] M. A. Redfern, J. Lopez, and R. O'Gorman, "A flexible protection scheme for multi-terminal transmission lines," in IEEE Power Engineering Society General Meeting, pp. 2678-2682 Vol. 3, Jun. 2005

[4] T. Zheng, Y. Zhao, J. Li, X. Wei, Y. Wang and Z. Wang, "A new pilot distance protection scheme for teed lines," 12th IET International Conference on AC and DC Power Transmission (ACDC 2016), Beijing, pp. 1-5, 2016 